\title{
Cyberbullying Involvement and Mental Health Problems Among Late Adolescents
}

\author{
Sara Skilbred-Fjeld ${ }^{1,2}$, Silje Endresen Reme ${ }^{1}$, \& Svein Mossige ${ }^{1}$ \\ ${ }^{1}$ Department of Psychology, University of Oslo, Oslo, Norway \\ ${ }^{2}$ Norwegian Social Research (NOVA), OsloMet - Oslo Metropolitan University, Oslo, Norway
}

\begin{abstract}
Exposure to cyberbullying is associated with psychological distress like depressive symptoms, self-injurious behavior and suicidal thoughts. Cyberbullying is thus a major challenge for public health. This study examines the prevalence of cyberbullying and explores the psychological characteristics of adolescents who have experienced cyberbullying. The sample consisted of 4531 Norwegian graduates in high school, age 18-21. The following psychological characteristics were investigated: self-harm, suicide attempts, antisocial behavior, anxiety and depression. Three mutually exclusive groups of cyberbullying were compared: 1) cybervictims, 2) cyberbullies and 3) cyberbully-victims. Participants involved in cyberbullying were further compared to those not involved. The prevalence of cyberbullying in this study was $5 \%$. There were no significant differences between cyberbullies, cybervictims and cyberbully-victims on any of the psychological variables, except for fewer reported suicide attempts in cyberbullies compared to cybervictims and cyberbully-victims. Late adolescents involved in cyberbullying did however report significantly more anxiety, depression, self-harm, suicide attempts and antisocial behavior, compared to those not involved. Thus, late adolescents involved in cyberbullying struggle more with psychological problems than non-involved adolescents. Increased knowledge about the characteristics of cyberbullies, cybervictims and cyberbully-victims could contribute to better detection and earlier identification of those involved in cyberbullying. This knowledge can further help understand more of the potential psychological vulnerability factors and consequences of cyberbullying, which could be used to optimize preventive measures and treatment.
\end{abstract}

Keywords: Cyberbully; cybervictim; depression; anxiety; suicide; antisocial behavior

\section{Introduction}

In recent years the awareness of- and focus on Internet related phenomenon like cyberbullying has increased (Wright et al., 2014). In Norway, 98\% of adolescents are connected to the Internet on a daily basis (Statistics Norway, 2016). For many late adolescents cyberbullying poses a threat to their health and well-being and has, amongst other things, consequences in terms of mental health problems such as anxiety and depression (Carvalho et al., 2017; Nixon, 2014; van Geel et al., 2014).

This study seeks to provide insight into some of the psychological characteristics related to cyberbullying involvement. More specifically, the purpose is to examine whether cyberbullies, cybervictims and cyberbully-victims differ, and if those involved in cyberbullying differ from non-involved when it comes to mental health problems such as psychological distress, self-destructive behavior, and antisocial behavior. 


\section{Cyberbullying and Traditional Bullying}

When it comes to defining cyberbullying, there are still some inconsistencies throughout the literature (Nixon, 2014). Cyberbullying has been defined as "an aggressive, intentional act carried out by a group or individual, using electronic forms of contact, repeatedly and over time against a victim who cannot easily defend him or herself" (Smith et al., 2008, p.376). Hinduja and Patchin (2015, p.11) define cyberbullying as "willful and repeated harm inflicted through the use of computers, cell phones and other electronic devices." The difficulty of defining cyberbullying may be due to the rapid development in technology and habits of communication, which has the potential to result in new methods of cyberbullying (Paul et al., 2012). Kofoed and Staksrud (2019) argue that it is problematic to base the definition of cyberbullying on that of traditional bullying, considering the differences between the two. Cyber- and traditional bullying have several commonalities (Kowalski \& Limber, 2013; Sourander et al., 2010), but differences between them are related to power imbalance (Hinduja \& Patchin, 2015; Slonje et al., 2013), repetition (Hinduja \& Patchin, 2015; Pelfrey \& Weber, 2013; Tokunaga, 2010) and anonymity (Dupper, 2013). Power imbalance and repetition are more easily identifiable in traditional bullying. Repetition is more unclear in cyberbullying because it might take only one post to be indefinitely reposted in different social media, websites and the like. Physical distance is another major characteristic of cyberbullying. Cyberbullies might be less aware of the impact of their behavior because they cannot see their victim's reaction to it (Bonanno \& Hymel, 2013). Whether anonymity can make the impact on the cybervictim worse is not agreed upon when students are asked. Some believe it has a huge impact, while others believe the opposite because the cybervictim is not hurt physically and can take avoiding action (Smith et al., 2008). Since the communication is often written (Monks et al., 2016), non-verbal cues and facial expressions may get lost (Nixon, 2014). Reduced social cues combined with anonymity and reduced adult supervision may lead to de-individualization and aggressive behavior (Yao \& Flanagin, 2006). When de-individualization occurs, people go along with what others are doing, which could also include cyberbullying. Cyberbullies may act meaner than they would if they were confronting the victim face-to-face due to online disinhibition and the lack of accountability cues (DeHue et al., 2008). Cyberbullying can take place any time and anywhere, making it hard to escape (Bonanno \& Hymel, 2013). Additionally, the potential audience is immense (Smith \& Slonje, 2010). Another interesting feature of cyberbullying that differentiates it from traditional bullying is the apparent easier path to the cyberbully-victim phenomena where cybervictims become cyberbullies or vice versa (Aboujaoude et al., 2015). Adolescents perceive visual abuse (photos and videoclips) and impersonation as most representative to the construct of cyberbullying (Naruskov et al., 2012). On the Internet, this material can spread quickly and exist for a long time (Brewer \& Kerslake, 2015).

\section{International Prevalence of Cyberbullying}

Prevalence rates of cyberbullying vary greatly due to the lack of a standard measuring instrument (Shapka \& Maghsoudi, 2017). A review of 159 studies across several countries observed prevalence rates from $1 \%$ to $61 \%$ for cybervictims, $3 \%$ to $39 \%$ for cyberbullies, and $2 \%$ to $72 \%$ for cyberbully-victims (Brochado et al., 2016). Hinduja and Patchin (2015) found prevalence rates of $12 \%$ cybervictims, $4 \%$ cyberbullies and $3 \%$ cyberbully-victims. These numbers are consistent across several studies (Livingstone et al., 2011; Rice et al., 2015).

\section{Mental Health Problems}

Previous studies have reported on higher levels of depressive symptoms, anxiety, low self-esteem, somatization and hostility in both cybervictims and cyberbullies (Kokkinos et al., 2014; Nixon, 2014; Tural Hesapcioglu \& Ercan, 2017). However, adolescents who have been shown to have the highest risk of developing mental health problems such as anxiety and depression are those who are both cyberbullies and victims (cyberbully-victims) (Brunstein Klomek et al., 2007; Dupper, 2013; Espelage \& Holt, 2013; Selkie et al., 2015). We thus expect to find the same in our study, and hypothesize that those who report both to be cyberbullies and victims will report the highest level of adverse mental health outcomes.

The mechanisms behind this could be understood cumulatively, in terms of a double load, where the adolescents are involved both as a victim and bully with all that that entails. But it could also be related to contextual factors - it has for instance been shown that this group of cyberbully-victims have a particularly poor parental attachment and report a high degree of peer rejection (Bayraktar et al., 2015).

Involvement in cyberbullying in any way has been associated with adverse mental health outcomes (Fahy et al., 2016; Patchin \& Hinduja, 2006), which we also expect to find in our study. But where most previous studies have focused 
primarily on depression and anxiety, we move beyond and investigate a broader specter of adverse mental health outcomes, including self-harm, suicide attempts, antisocial behavior. We hypothesize that involvement in cyberbullying will be associated with all of these adverse mental health outcomes.

\section{Cyberbullying, Self-Destructive Behavior and Antisocial Behavior}

Olweus (1994) found that bully-victims are characterized by a combination of anxious and aggressive behaviors. The Internet's nature may offer already aggressive adolescents a further medium to act out through. Cyberbullies have correspondingly been found to score high on proactive aggression (Sontag et al., 2011), which means that cyberbullies also practiced other aggressive behavior with the aim of achieving social gain. Cyberbullying as an aggressive behavior may further be associated with antisocial behavior (Sticca et al., 2013). Campbell et al. (2013) argue that cyberbullies are more likely to show other problem behavior, like antisocial behavior, in addition to being less likely to engage in prosocial behaviors. Although few studies have looked at the mental health characteristics of cyberbullies specifically, more social difficulties (Campbell et al., 2013) higher drug use, and aggressive behavior (Carvalho et al., 2017) have been reported in this group.

While self-destructive behavior, such as self-harm and suicidal behavior, are not usually thought of as aggressive acts, they could be considered aggression turned inwards. The conceptual framework of the current study draws on Robert Plutchik's theory of suicide and violence that may help us understand this further. The two-stage model of suicide and violence developed by Plutchik (1995) is a theory that can provide an understanding of cyberbullies' and cybervictims' mental health. Plutchik claims that both suicide and violence are aggressive impulses, which are affected by other variables like mental illness, family network, coping strategies etc. These variables may influence whether the aggression is turned inwards (self-harm/suicide) or outward (violent actions). Aggression is defined as an act with the intention to harm anyone physically or mentally (Berkowitz, 1993). Cyberbullying could as such be considered to be an aggressive and intentional act. Based on Plutchik's theory, we see both cyberbullying others and harming oneself as aggressive acts. Cybervictims might turn the aggression towards themselves through self-harm and suicide attempts, whereas cyberbullies might be more prone to turn the aggression towards others. We thus hypothesize that cybervictims will present with more self-destructive behavior, while cyberbullies will present with more antisocial behavior.

In a review Dutton and Karakanta (2013) mention a number of studies that report increased likelihood of aggression in people with depression. For example, negative life events causing depression could lead to aggressive behavior towards people perceived as aversive. Others have found both problem behavior (aggression, delinquency, substance use) and depressed mood in 8.-10. graders to be predictors of involvement in cyberbullying as cybervictims and cyberbullies in 11. grade (Modecki et al., 2013). These associations are important to consider in the attempts of trying to understand and prevent cyberbullying. Still findings are scarce and often inconsistent within this field (Bayraktar et al., 2015). Therefore more knowledge is needed about the specific psychological characteristics of adolescents involved in cyberbullying - both in terms of differences between cybervictims, cyberbullies and cyberbully-victims, but also with regards to psychological characteristics of all those involved in cyberbullying compared to adolescents that are not involved in cyberbullying. No studies have so far looked specifically at both aggression turned inwards and outwards, as well as symptoms of depression and anxiety in cyberbullies, cybervictims cyberbully-victims.

The aim of the current study was thus to illuminate these issues by analyzing the responses from a large and representative survey of Norwegian adolescents, through the following research questions: 1) What is the prevalence of cyberbullying among late adolescents in high school? 2) Are there significant differences between cyberbullies, cybervictims and cyberbully-victims when it comes to psychological distress, self-destructive behavior and antisocial behavior? 3) Are there significant differences between those involved in cyberbullying and those not involved in cyberbullying in terms of psychological distress, self-destructive behavior and antisocial behavior? 4) Are the prevalence rates and/or associations influenced by sociodemographic variables? Besides from gender and age, we were particularly interested in perceived financial situation (as an indication of socioeconomic status), and birth place (as an indication of ethnicity), in order to investigate for possible discrimination effects and confounding.

Answers to these questions may contribute to a deeper understanding of how the various types of cyberbullying involvement relate to psychological distress more generally, as well as self-destructive and antisocial behavior specifically, with potential implications for intervention and prevention. 


\section{Method}

\section{Participants}

This study uses data material from a cross-sectional study carried out by Norwegian Social Research Institute (NOVA) in 2015. All the data were collected through self-report, filled out by the participants. The participants were seniors in high school in a nationally representative sample of secondary schools in Norway, that is late adolescents aged 18 to 21 years. A total of 6848 late adolescents were asked to respond to a self-report questionnaire. Classes and groups with a lower response rate than $10 \%$ were excluded from the data analysis as it was assumed that schools had not followed the study instructions and thus could represent a risk of selection bias if they were included. 4531 of the 6848 requested students filled out the questionnaire, which makes up a response rate of $66 \%$.

\section{Recruitment}

The survey (Mossige \& Stefansen, 2016) is a follow-up study of a survey conducted in 2007. In the first survey schools were selected by the Norwegian statistics bureau. First, all senior high schools in Norway were categorized into five geographical strata to ensure geographical representativeness. Second, the schools were stratified within each region according to academic high schools, vocational high schools, and schools with both curricula (3 strata). The 67 participating schools were thereafter drawn according to strata size, ensuring proportional allocation and grouped into five geographic regions. 41 of the 67 participating schools in 2007 agreed to participate in the 2015 study. In addition, eight replacement schools attended and thus 49 schools attended in total. Contact with the schools first took place through e-mail to inform them about the study, and later through telephone contact with the principals. At each school the principal designated a contact person who was responsible for conducting the study, as well as maintaining contact between the school and NOVA.

\section{Procedure}

The study was assessed and advised by The Norwegian Center for Research Data (NSD). NSD then applied to The Norwegian Data Protection Authority for license, which was granted. Before the study started the school's contact persons received information on how to conduct the study by the company Conexus. The company arranged the electronic solution so they could log onto an order portal and receive the correct number of user names. Students completed the questionnaire on computers at school during school hours with a teacher present, and was handled as an examination. Students who did not want to participate or canceled their participation throughout the study $(n=2318$, $34 \%)$ had to perform other school work the remaining time. The survey was anonymous and the students' identities cannot be traced. The entire questionnaire consisted of 142 questions.

\section{Measures}

Socio-demographic variables. Information was collected concerning participants' gender, age (i.e., date of birth), education (general studies/sports/music, dance and drama/arts and crafts/electrical subjects/health and social care/media and communication/natural resource/service and transport/technique and industrial production), country of birth, as well as country of birth of their mother and father, and their perception of the financial situation of the family (poor/unstable or good/stable). Country of birth was recoded for analysis to "Norway" versus "other". Education was recoded to "general studies" versus "vocational studies". See Table 1 for descriptives.

Cyberbullies, cybervictims and cyberbully-victims. Cyberbullying was measured by question batteries, asking about experiences with being a cyberbully, cybervictim and cyberbully-victim. These questions were developed by Hinduja and Patchin (2015) to identify specific experiences with cyberbullying; Cronbach's alpha is $\geq .90$ for the cyberbullying victimization scale, as well as for the cyberbullying offending scale. Prior to the present study, the questions were translated into Norwegian by the research team. The questions were as follows: "I have been cyberbullied in these ways during the past month" (cyberbullying victimization scale) and "I have cyberbullied others in these ways during the past month" (cyberbullying offending scale). Each of the issues raised was followed by eight items about experiences with various forms of cyberbullying. Participants who had been cybervictims could for example tick off: "Someone posted a mean or hurtful picture of me online." For cyberbullies the corresponding question was: "I posted a mean or hurtful picture of someone online." The participants rated their responses on a 5-point likert scale: 1) "Never", 2) "Once", 3) "A 
few times", 4) "Several times" and 5) "Many times". The cyberbullying forms included in the questionnaire were related to experiences with mean or hurtful comments, photos, videos, websites, rumor spreading, threats of harm or identity theft (pretending to be someone else). The present study categorized late adolescents with "a few", "several" and "many" cyberbullying experiences into three mutually exclusive groups: cyberbullies, cybervictims and cyberbully-victims. Those answering "a few", "several" and "many times" at least once on the victimization scale, but answering "never" or "once" on the aggression scale were considered exclusively victims. Those who answered "a few", "several" and "many times" at least once on the aggression scale, but answered "once" or "never" on the victimization scale were considered exclusively aggressors.

The eight different cyberbullying forms were weighted equally, since all of them can be equally damaging for the individual experiencing cyberbullying. Not all experiences with cyberbullying are the same, but it is difficult to weight them objectively since each person's experience is unique. Albeit a previous study found some support for one particular type of bullying (picture - and video clip bullying) being worse than others (e.g. text messaging and phone calls) (Smith et al. 2008), but the technological changes and digital habits of young people change fast and this could have a profound impact on the experience of the various forms of cyberbullying. Thus, we chose to weight the different types of cyberbullying equally, which is also in line with a recent and validated measure of cyberbullying victimization and offending (Hinduja \& Patchin, 2015).

Self-harm. The questionnaire also included questions about self-harm. These questions were selected based on what has been used in previous similar studies. Three questions asked about self-harm: Have you ever "hurt yourself, for example by cutting yourself?", "been to the emergency room due to hurting yourself on purpose?" and "ended up in hospital due to hurting yourself on purpose?". The variable was dichotomized so that 1 indicated at least one episode of self-harm, whilst 0 indicated no such experiences.

Suicide attempts. Three questions asked about suicide attempts: Have you ever "deliberately taken an overdose of pills or other medications?", "tried to end your life?" and "ended up in hospital due to trying to end your life?" The answering options were "never", "once" and "several times". These questions about suicidal behavior were taken from the Norwegian Social Research study "Ung i Oslo longitudinell" (LUNO) - Young in Oslo Longitudinal". The variable describing suicide attempts was dichotomized so that 1 indicated at least one episode of suicide attempt, whilst 0 indicated no such experiences.

Antisocial behavior. Five questions asked about antisocial behavior. These were the same as those used in the 2007 study and were selected based on what previous studies have reported about externalizing behavior (Camodeca et al., 2002; Nansel et al., 2004; Stein et al., 2007). Questions about antisocial behavior (in the past 12 months) in this study dealt with vandalism, theft, threatening others in order to get money, burglary and fighting (with weapons, such as knives). The variable was dichotomized so that 1 indicated at least one episode of antisocial behavior whilst 0 indicated no such experiences.

Anxiety and depression. Anxiety and depression were measured using the Hopkins Symptom Checklist (HSCL-25) translated into Norwegian, which is a self-report form consisting of 25 questions. Ten of the questions intend to measure anxiety and fifteen of the questions measure depression. The response options were rated on a 4-point scale: 1) "Not bothered at all", 2) "A little bothered", 3) "Quite a bit bothered" and 4) "Extremely bothered". In the current sample, the Cronbach's alpha for the depression subscale was .93, while Cronbach's alpha for the anxiety subscale was .88. The optimal cutoff (for the entire scale) when compared to psychiatric interviews in a Norwegian study, were found to be $\geq 1.75$ in women and somewhat lower in men (Sandanger et al., 1998). The same cutoff ( $\geq 1.75$ ) was also found to be the preferred option in a Swedish study, and this cutoff was thus chosen as an indication of depression and anxiety for both boys and girls in the current study, although we use the subscales both as continuous and categorical variables. We use the scale as a continuous measure to indicate level of psychological distress, and as a categorical measure to indicate possible caseness of depression and anxiety. With regards to the ability to predict diagnoses of anxiety and depression, the entire HSCL-25 scale was found to be just as good as the anxiety and depression subscales of the HSCL-25 (Sandanger et al., 1998).

Data analysis. The computer program SPSS version 22 was used for all statistical analyzes. To describe background variables for the entire sample frequency tables were used, and chi-square tests were used to compare the groups cyberbully, cybervictim and cyberbully-victim on background variables and target variables. Distribution and outliers for all investigated variables were checked. Independent samples t-test was used to compare those involved in cyberbullying (all three groups combined) to those not involved in cyberbullying. Due to the large sample size of the two groups 
compared in this analysis $(n=>200)$, a slightly skewed distribution on some variables were not considered a problem (Tabachnick, Fidell, \& Osterlind, 2001). To investigate adjusted associations between exposure to bullying and target variables, we used logistic regression analyses. Independent variables were tested for multicollinearity, and based on the high correlation between the depression and anxiety subscale, it was decided to only include total score of HSCL-25.

\section{Results}

Of all participants ( $n=4531)$, nearly $5 \%(n=208)$ reported being involved in cyberbullying in the last month. $3 \%$ of these were cybervictims, $1 \%$ were cyberbullies and $1 \%$ were cyberbully-victims. Among those involved, $68 \%(n=142)$ were cybervictims, $16 \%(n=33)$ were cyberbullies and $16 \%(n=33)$ were cyberbully-victims. Fifty-three percent of them were girls, with an average age of 19.5 years. Ninety-three percent took general education and $5.5 \%$ took vocational studies. See Table 1 for more demographic and background characteristics.

Table 1. Description of all Participants ( $n=4531)$, as well as a Statistical Comparison Between the 3 Groups Reporting Involvement in Cyberbullying $(n=208)$.

\begin{tabular}{|c|c|c|c|c|c|c|c|c|c|}
\hline & \multicolumn{2}{|c|}{ Total } & \multicolumn{2}{|c|}{ Cybervictim } & \multicolumn{2}{|c|}{ Cyberbully } & \multicolumn{2}{|c|}{ Cyberbully-victim } & \multirow[b]{2}{*}{$x^{2}$} \\
\hline & $n$ & $\%$ & $n$ & $\%$ & $n$ & $\%$ & $n$ & $\%$ & \\
\hline Gender: & & & & & & & & & $8.10^{*}$ \\
\hline Male & 1822 & 40.8 & 59 & 41.5 & 21 & 70.0 & 16 & 48.5 & \\
\hline Female & 2644 & 59.2 & 83 & 58.5 & 9 & 30.0 & 17 & 51.5 & \\
\hline Age: & & & & & & & & & 4.38 \\
\hline $18-19$ & 4198 & 93,7 & 131 & 92.9 & 33 & 100 & 31 & 96.9 & \\
\hline$\geq 20$ & 284 & 6.3 & 10 & 7.1 & 0 & 0 & 1 & 3.1 & \\
\hline Education: & & & & & & & & & 3.81 \\
\hline General & 4218 & 94.5 & 131 & 92.3 & 33 & 100 & 29 & 87.9 & \\
\hline Vocational & 245 & 5.5 & 11 & 7.7 & 0 & 0 & 4 & 12.1 & \\
\hline Family finances: & & & & & & & & & 2.90 \\
\hline Good & 4122 & 92.4 & 121 & 87.1 & 30 & 90.9 & 32 & 97.0 & \\
\hline Poor/unstable & 340 & 7.6 & 18 & 12.9 & 3 & 9.1 & 1 & 3.0 & \\
\hline \multicolumn{10}{|l|}{ Birth place: } \\
\hline Mother: & & & & & & & & & 0.24 \\
\hline Norway & 3915 & 87.0 & 120 & 84.5 & 27 & 81.8 & 27 & 81.8 & \\
\hline Foreign country & 586 & 13.0 & 22 & 15.5 & 6 & 18.2 & 6 & 18.2 & \\
\hline Father: & & & & & & & & & 0.22 \\
\hline Norway & 3889 & 86.5 & 120 & 85.1 & 27 & 81.8 & 28 & 84.8 & \\
\hline Foreign country & 607 & 13.5 & 21 & 14.9 & 6 & 18.2 & 5 & 15.2 & \\
\hline Participant: & & & & & & & & & 0.66 \\
\hline Norway & 4178 & 92.8 & 131 & 92.3 & 29 & 87.9 & 30 & 90.9 & \\
\hline Foreign country & 324 & 7.2 & 11 & 7.7 & 4 & 12.1 & 3 & 9.1 & \\
\hline Self-harm & 656 & 14.5 & 41 & 28.9 & 5 & 15.2 & 10 & 30.3 & 2.79 \\
\hline Suicide attempt & 352 & 7.2 & 27 & 19.0 & 1 & 3.0 & 9 & 27.3 & $7.09 *$ \\
\hline Antisocial behavior & 301 & 6.6 & 25 & 17.6 & 5 & 15.2 & 7 & 21.2 & 0.43 \\
\hline Depression $(\geq 1.75)$ & 1683 & 39.8 & 96 & 69.6 & 16 & 50.0 & 23 & 69.7 & 4.64 \\
\hline Anxiety $(\geq 1.75)$ & 1208 & 28.6 & 77 & 56.6 & 15 & 56.9 & 19 & 57.6 & 1.08 \\
\hline
\end{tabular}

Note. ${ }^{*} p<.05$. 


\section{Differences Between Cyberbullies, Cybervictims and Cyberbully-Victims}

Gender. There were significant gender differences between cyberbullies, cybervictims and cyberbully-victims $(p<.05)$, as shown in Table 1. More boys than girls belonged to the group of cyberbullies, while more girls belonged to the group of cybervictims.

Age. No significant age differences were found between the groups. As shown in Table 1, all of the participants involved in cyberbullying were $18-19$ years old compared to $92.9 \%$ of the cybervictims, but the difference was not statistically significant $(p>.05)$.

Education. All participants involved as cyberbullies took general studies compared to only $87.9 \%$ of cyberbully-victims and $92.3 \%$ of cybervictims, but the differences were not statistically significant $(p>.05)$.

Family finances and birth place. Most of those involved in cyberbullying reported good family finances, with somewhat fewer in the cybervictim group; $87.1 \%$ of cybervictims, $90.9 \%$ of cyberbullies and $97.0 \%$ of cyberbully-victims reported good family finances. Most participants involved in cyberbullying were born in Norway. $84.5 \%$ of the cybervictims' mothers and fathers were born in Norway and $92.3 \%$ of the cybervictims themselves were born in Norway. The cyberbullies' parents were mostly also born in Norway (parents: $81.8 \%$ ) and $87.9 \%$ of the cyberbullies themselves were born in Norway. Cyberbully-victims' parents were mostly also born in Norway ( $81.8 \%$ of the mothers, $84.8 \%$ of fathers) and $90.9 \%$ of cyberbully-victims themselves were born in Norway.

Mental health. The only significant difference between the three cyberbully groups were on suicide attempt, where a significantly lower proportion of cyberbullies reported of suicide attempt compared to cybervictims and cyberbullyvictims. There were no other significant differences between the groups on neither anxiety, depression, self-harm nor antisocial behavior.

Table 2. Comparison of Late Adolescents Involved $(n=208)$ and Not-Involved $(n=4323)$ in Cyberbullying. T-Tests Were Used for Continuous Variables and Chi-Square for Categorical Variables.

\begin{tabular}{|c|c|c|c|c|c|}
\hline & \multicolumn{2}{|c|}{ Non-involved } & \multicolumn{2}{|c|}{ Involved } & \multirow[b]{2}{*}{$t / \chi^{2}$} \\
\hline & $M$ & $S D$ & $M$ & $S D$ & \\
\hline HSCL anxiety & 1.54 & .52 & 1.96 & .71 & $8.21^{\star \star \star}$ \\
\hline HSCL depression & 1.72 & .63 & 2.17 & .74 & $8.50^{\star \star \star}$ \\
\hline \multirow[t]{2}{*}{ HSCL total score } & 1.65 & .56 & 2.08 & .69 & $8.77^{\star \star *}$ \\
\hline & $\%$ & $N$ & $\%$ & $N$ & \\
\hline Depression $\geq 1.75$ & 38.5 & 1548 & 66.5 & 135 & $62.12^{* * *}$ \\
\hline Anxiety $\geq 1.75$ & 27.3 & 1097 & 55.2 & 111 & $71.81^{* * *}$ \\
\hline Total over cut-off $\geq 1.75$ & 35.5 & 1422 & 64.7 & 130 & $69.00^{\star \star *}$ \\
\hline Self-harm & 13.9 & 600 & 26.9 & 56 & $27.27^{* * *}$ \\
\hline Antisocial behavior & 6.1 & 264 & 17.8 & 37 & $43.67^{\star \star \star}$ \\
\hline Suicide attempt & 6.7 & 288 & 17.8 & 37 & $36.90^{\star \star \star}$ \\
\hline Gender: & & & & & 3.24 \\
\hline Male & 40.50 & 1726 & 46.80 & 96 & \\
\hline Female & 59.50 & 2535 & 53.20 & 109 & \\
\hline Education: & & & & & 1.25 \\
\hline General & 94.6 & 4025 & 92.8 & 193 & \\
\hline Vocational & 5.4 & 230 & 7.2 & 15 & \\
\hline Family finances: & & & & & 2.96 \\
\hline Good & 92.5 & 3939 & 89.3 & 183 & \\
\hline Bad/unstable & 7.5 & 318 & 10.7 & 22 & \\
\hline
\end{tabular}

Note. ${ }^{*} p<.05,{ }^{*} p<.01,{ }^{* \star *} p<.001$. 


\section{Differences Between Those Involved and Those not Involved in Cyberbullying}

After comparing cybervictims, cyberbullies and cyberbully-victims, these three groups were combined into one group. The combined group called "involved" did not differ from the non-involved on any of the sociodemographic variables. They did, however, differ significantly on all the mental health outcomes in that the late adolescents involved in cyberbullying reported significantly more involvement in self-harm, suicide attempts, antisocial behavior, anxiety and depression (Table 2). Nearly twice as many in the involved (64.7\%) scored above the clinical cut-off (1.75) on HSCL-25, compared with those not involved (35.5\%).

We also investigated the association between involvement and non-involvement in cyberbullying and psychological outcomes through multivariate statistics (regression analysis), with involvement in cyberbullying as the outcome variable, and psychological distress, suicide attempt, self-harm and antisocial behavior as the independent variables (Table 3). Involvement in cyberbullying was significantly associated with the vast majority of mental health outcomes, even when controlling for demographic variables (age, gender, family finance and birth place).

Table 3. Associations Between Demographics and Mental Health Outcomes and Involvement in Cyberbullying (Adjusted Logistic Regression Model)*.

\begin{tabular}{lccccc}
\hline & \multicolumn{5}{c}{ Involvement in cyber bullying } \\
\cline { 2 - 6 } & $B$ & $S E$ & $O R$ & $95 \% \mathrm{Cl}$ & $p$-value \\
\hline Age (18-19) & 0.61 & 0.36 & 1.83 & {$[0.27,1.10]$} & .09 \\
Gender (female) & -0.74 & 0.17 & 0.48 & {$[0.34,0.66]$} & $<.001$ \\
Family finance (poor/unstable) & 0.15 & 0.25 & 1.17 & {$[0.72,1.89]$} & .54 \\
Birth place: mother (Norway) & -0.49 & 0.28 & 0.61 & {$[0.35,1.06]$} & .08 \\
Birth place: father (Norway) & 0.12 & 0.30 & 1.12 & {$[0.63,2.00]$} & .69 \\
Birth place: participant (Norway) & 0.05 & 0.37 & 1.05 & {$[0.51,2.16]$} & .89 \\
Psychological distress (total score $\geq 1.75)$ & 1.27 & 0.17 & 3.57 & {$[2.54,5.02]$} & $<.001$ \\
Self-harm & 0.37 & 0.20 & 1.44 & {$[0.97,2.15]$} & .07 \\
Suicide attempt & 0.51 & 0.23 & 1.66 & {$[1.05,2.63]$} & .03 \\
Antisocial behavior & 0.82 & 0.21 & 2.26 & {$[1.50,3.42]$} & $<.01$ \\
\hline
\end{tabular}

Note. ${ }^{*}$ All variables are dummy coded with 0 as reference category and 1 stated in parentheses.

\section{Discussion}

The aim of this study was to investigate expressions of aggression turned inwards and outwards, as well as symptoms of depression and anxiety among late adolescents involved in cyberbullying. Through a large, representative cross-sectional study of more than $\mathbf{4 5 0 0}$ late adolescents in high school, prevalence and characteristics of cyberbullies, cybervictims and the combination of the two were investigated. The prevalence of cyberbullying in this population was $5 \%$. Those who reported experiences with cyberbullying were divided into three mutually exclusive groups. We wanted to investigate whether cybervictims, cyberbullies and cyberbully-victims were significantly different concerning psychological characteristics.

Our prevalence figures of $3 \%$ cybervictims, $1 \%$ cyberbullies and $1 \%$ cyberbully-victims are consistent with previous research findings (Hinduja \& Patchin, 2015; Kowalski \& Limber, 2013; Olweus, 2012; Rice et al., 2015; Wendelborg, 2012). Next we wanted to compare all those involved in cyberbullying (cybervictims, cyberbullies and cyberbully-victims) with the rest of the study population (non-involved) on adverse mental health outcomes. The results demonstrated statistically significant differences between the involved and non-involved on the vast majority of psychological outcomes. The late adolescents involved in cyberbullying had a close to four-fold risk of anxiety and depression, they were more than twice as likely to be involved in antisocial behavior, and were more likely to have attempted suicide. This was in line with our hypothesis that all those involved in cyberbullying, whether it is on the bully or victim side, represent a particularly vulnerable group. 


\section{Psychological Distress and Self-Injurious Behavior}

Cyberbully-victims reported the highest rates of suicide attempts among the three groups involved in cyberbullying, which was in line with our hypothesis. Exposure to cyberbullying is related to higher risk of suicide attempts, and cyberbully-victims seem to be a particularly vulnerable group consistent with theory and research findings (Brunstein Klomek et al., 2007; Dupper, 2013; Espelage \& Holt, 2013; Lien \& Welander-Vatn, 2013). Suicide attempt is a serious problem among cybervictims and cyberbully-victims, as indicated in our study. In previous studies (Brunstein Klomek et al., 2007; Lien \& Welander-Vatn, 2013) both frequent and infrequent involvement in cyberbullying was found to increase the risk of suicidal thoughts and suicide attempts. According to Hinduja and Patchin (2015) it is important to stress that cyberbullying itself most likely does not lead to suicide attempts. Cyberbullying can, however, contribute to aggravating an already stressful life situation further, which in turn may increase the likelihood of suicidal thoughts and suicide attempts.

\section{Depression, Anxiety and Self-Harm}

Contrary to our hypotheses, we did not find significant differences between cyberbullies, cybervictims and cyberbullyvictims in depressive symptoms. Tendencies of more depressive symptoms among cyberbully-victims than cyberbullies and cybervictims were not statistically significant. Several studies indicate most depression among cyberbully-victims (Brunstein Klomek et al., 2007; Dupper, 2013; Kowalski \& Limber, 2013; Selkie et al., 2015), but this was not supported in our study. Hinduja and Patchin (2010) found that adolescents involved in cyberbullying struggle more than non-involved adolescents when it comes to suicidal ideation, which is related to depression. This supports our finding of significantly more depression among those involved with cyberbullying compared with those not involved.

Based on previous empirical findings (Hawker \& Boulton, 2000; Lien \& Welander-Vatn, 2013), we expected to find more self-harm and more anxiety among cybervictims than among cyberbullies. Self-harm may be related to anxiety and depression (Crowe, 2014). However, our results did not confirm more self-harm in cybervictims and cyberbully-victims than among cyberbullies, as these differences did not reach statistical significance. The findings on these psychological characteristics may imply that cyberbullies and cybervictims self-harm just as much, and that measures against selfharming thus should be directed towards helping both cybervictims and cyberbullies. Furthermore, with $65 \%$ of those involved in cyberbullying scoring above the clinical cut-off on HSCL-25, anxiety and depression seem to be a serious problem among late adolescents with any type of cyberbullying experience.

\section{Gender Differences}

Research findings regarding gender differences in cyberbullying are inconclusive (S. K. Schneider et al., 2012). We found that more girls than boys were cybervictims and that more boys than girls were cyberbullies, which is in line with our hypothesis and some previous findings (Beckman et al., 2013; Wang et al., 2009). However, Beckman et al. concluded that 1) girls are just as likely to be cyberbullies as boys, 2) girls are more likely to be cyberbully-victims and 3) more girls than boys are cybervictims. Other research also suggests that girls are involved in cyberbullying as cyberbully-victims (Smith et al., 2008; Sourander et al., 2010). In cyberbullying the gender differences seem to be less prominent than in traditional bullying. Sourander et al. argue that boys typically are physically stronger than girls, and since cyberbullying does not call for physical strength, girls could to a greater extent dare to bully others online. Adolescent girls tend to participate in more indirect forms of bullying, like rumor spreading and socially excluding peers (Bowie, 2007). Therefore, the verbal and relational nature of cyberbullying fits closely with female socialization practices (Wade \& Beran, 2011).

\section{Theoretical Reflections}

Just a few previous studies have examined the relationship between cyberbullying and involvement in other antisocial behavior. Ybarra and Mitchell (2004) found antisocial behavior like damaging property, consumption of cigarettes and alcohol to be associated with cyberbullies, while others suggest that antisocial behavior, such as rule-breaking behavior and traditional bullying, increase the risk of cyberbullying involvement (Sticca et al., 2013). It is argued that cyberbullying may be an additional way of attacking people. An American study (Wang et al., 2012) with over 7,000 adolescents found that most cyberbullies belonged to a group of aggressive adolescents who were related to substance abuse and weapon possession. The problems were particularly related to boys. It is thus argued that the online world may offer already aggressive youth an additional medium to act out through, and that these students probably could be identified as aggressive by teachers, fellow students or parents in offline situations (Sontag et al., 2011). 
Our findings provide new knowledge about how cyberbullying and antisocial behavior are interrelated. Unlike the aforementioned research, we did not find a significant correlation between cyberbullying and antisocial behavior. This indicates that late adolescents involved in cyberbullying (as a cyberbully, cybervictim or cyberbully-victim) are equally aggressive. Cyberbullying might rather happen due to the nature of the Internet, where less direct contact and less salient power imbalances might lead to individuals reacting in a more aggressive manner due to loss of inhibitions and consequences (Sticca et al., 2013).

We did, however, find that cyberbullies, cybervictims and cyberbully-victims differed in relation to suicide attempts. Although the cross-sectional nature of our study precludes any causal inferences, cybervictims and cyberbully-victims appears to be the most vulnerable to attempt suicide. Finally, few significant differences between cyberbullies, cybervictims and cyberbully-victims may imply that they are quite similar.

In his model of suicide and violence Plutchik (1995) states that depression, hopelessness, life problems and impulsivity correlate significantly with both suicide and aggression. Therefore, the risk of turning the aggression inwards (self-harm, suicide attempts) or outwards (against others) increases. Suicide is strongly related to mental disorders, especially depression (B. Schneider et al., 2014). Depression and aggression are thus not mutually exclusive (Dutton \& Karakanta, 2013; Modecki et al., 2013). Plutchik's theory can thereby help to explain the present study's finding that cyberbullies, cybervictims and cyberbully-victims struggle equally with depression and aggression. Our finding that cyberbully-victims are more vulnerable to attempt suicide than cybervictims can be explained by this group's double load in terms of experiencing both inward- and outward aggression through self-harm and harming others.

\section{Limitations}

The study population in the present study consisted of senior graduates in high schools. Those who never entered or dropped out of high school (approximately $30 \%$ of an age cohort) are not part of this sample. This group may include several late adolescents involved in cyberbullying. The current results can therefore not be generalized to this group of late adolescents. Further, some school classes were excluded from the study as they had responded to less than $10 \%$ of the survey and thus were assumed to have not followed the instructions. This could represent a potential bias. However, as the overall response rate was relatively high (66\%) we do not consider this a threat to the external validity of the findings.

The questions about cyberbullying in this study sought insight into cyberbullying experiences during the past month. This wording will exclude late adolescents who have experienced cyberbullying in an extended period of time. Nevertheless, recent memories are more present and reporting cyberbullying experiences could therefore be more precise. It is easier to remember how many times you have experienced cyberbullying the past month than the last year.

There is a possibility that higher suicide attempts among cyberbully-victims may be due to a statistical artifact. There may have been too few people in the group of cyberbullies to show the actual prevalence, which underlines the need for follow-up studies with greater statistical power. We also encourage follow-up studies with longitudinal designs to be able to assess directionality of the associations found in the current study.

The proportion of youths in the whole study population that scored above the clinical cut-off on HSCL was very high (36\%). This is in line with recent Norwegian reports documenting a significant increase of psychological distress in this particular age group, but it could also be due to the cut-off we used $(\geq 1.75)$ which has not been validated for this particular population.

According to Bakken (2018) the extent of self-reported depressive symptoms has gradually increased among girls since the beginning of the 2010s. Over the past two years, the increase has been substantial, especially in high school. Also among boys, Bakken's latest figures show an increase in the extent of depressive symptoms.

\section{Implications for Research and Practice}

We found remarkably high rates of depression among late adolescents involved in cyberbullying. Sixty-five percent of those involved scored above the clinical cut-off (1.75) on the depression sub-scale of HSCL-25. These scores indicate a need for treatment, since a score above the cut-off on $\mathrm{HSCL}$ is an indication of requiring treatment for mental disorders. This issue should be followed up in further studies and in treatment practices. 


\section{Conclusion}

In this study of the prevalence and psychological characteristics of cyberbullying in a large cohort of seniors in high school, five percent of the late adolescents had been involved in cyberbullying. We found cyberbullies, cybervictims and cyberbully-victims to be quite similar in terms of depression and aggression, but the groups combined differed from the students that were not involved in cyberbullying. Also, $65 \%$ of those involved in cyberbullying scored above the clinical cut-off on a symptom scale of depression and anxiety. Since most of the late adolescents involved in cyberbullying appear to be struggling with symptoms of anxiety and depression, this should be taken into account in the follow-up and possible treatment of these individuals. Cyberbullies, cybervictims and cyberbully-victims appear to be more similar than expected in terms of psychological distress, self-destructive behavior and antisocial behavior, which could provide treatment implications. Cybervictims, cyberbullies and cyberbully-victims were more vulnerable than those not involved in cyberbullying in terms of depression, anxiety, self-harm, suicide attempts and antisocial behavior. Increased knowledge about the psychological characteristics of cyberbullies, cybervictims and cyberbully-victims could contribute to better detection and earlier identification of those involved in cyberbullying. This knowledge can further help to understand more of the potential psychological vulnerability factors and consequences of cyberbullying, which could be used to optimize preventive measures and treatment.

\section{Acknowledgement}

The authors wish to thank The Norwegian Social Research Institute (NOVA) and all the students that participated in this survey.

\section{References}

Aboujaoude, E., Savage, M. W., Starcevic, V., \& Salame, W. O. (2015). Cyberbullying: Review of an old problem gone viral. Journal of Adolescent Health, 57(1), 10-18. https://doi.org/10.1016/j.jadohealth.2015.04.011

Bakken, A. (2018). Ungdata. Nasjonale resultater 2018 [National results 2019] (NOVA report 8/18). Nova.

http://www.hioa.no/Om-OsloMet/Senter-for-velferds-og-

arbeidslivsforskning/NOVA/Publikasjonar/Rapporter/2018/Ungdata-2018.-Nasjonale-resultater

Bayraktar, F., Machackova, H., Dedkova, L., Cerna, A., \& Ševčíková, A. (2015). Cyberbullying: The discriminant factors among cyberbullies, cybervictims, and cyberbully-victims in a Czech adolescent sample. Journal of Interpersonal Violence, 30(18), 3192-3216. https://doi.org/10.1177/0886260514555006

Beckman, L., Hagquist, C., \& Hellström, L. (2013). Discrepant gender patterns for cyberbullying and traditional bullying - An analysis of Swedish adolescent data. Computers in Human Behavior, 29(5), 1896-1903.

https://doi.org/10.1016/j.chb.2013.03.010

Berkowitz, L. (1993). Aggression: Its causes, consequences, and control. McGraw-Hill Book Company.

Bonanno, R. A., \& Hymel, S. (2013). Cyber bullying and internalizing difficulties: Above and beyond the impact of traditional forms of bullying. Journal of Youth and Adolescence,42(5), 685-697. https://doi.org/10.1007/s10964-0139937-1

Bowie, B. H. (2007). Relational aggression, gender, and the developmental process. Journal of Child and Adolescent Psychiatric Nursing, 20(2), 107-115. https://doi.org/10.1111/j.1744-6171.2007.00092.x

Brewer, G., \& Kerslake, J. (2015). Cyberbullying, self-esteem, empathy and loneliness. Computers in Human Behavior, 48, 255-260. https://doi.org/10.1016/j.chb.2015.01.073

Brochado, S., Soares, S., \& Fraga, S. (2016). A scoping review on studies of cyberbullying prevalence among adolescents. Trauma, Violence, \& Abuse, 18(5), 523-531. https://doi.org/10.1177/1524838016641668 
Brunstein Klomek, A., Marrocco, F., Kleinman, M., Schonfeld, I. S., \& Gould, M. S. (2007). Bullying, depression, and suicidality in adolescents. Journal of the American Academy of Child \& Adolescent Psychiatry, 46(1), 40-49.

https://doi.org/10.1097/01.chi.0000242237.84925.18

Camodeca, M., Goossens, F. A., Terwogt, M. M., \& Schuengel, C. (2002). Bullying and victimization among school-age children: Stability and links to proactive and reactive aggression. Social Development, 11(3), 332-345.

https://doi.org/10.1111/1467-9507.00203

Campbell, M. A., Slee, P. T., Spears, B., Butler, D., \& Kift, S. (2013). Do cyberbullies suffer too? Cyberbullies' perceptions of the harm they cause to others and to their own mental health. School Psychology International, 34(6), 613-629.

https://doi.org/10.1177/0143034313479698

Carvalho, M., Branquinho, C., \& Matos, M. G. D. (2017). Cyberbullies, cybervictims and cyberbullies-victims: Discriminant factors in Portuguese adolescents. Psicologia, Saúde \& Doenças, 18(3), 657-668.

http://dx.doi.org/10.15309/17psd180303

Crowe, M. (2014). From expression to symptom to disorder: The psychiatric evolution of self-harm in the DSM. Journal of Psychiatric and Mental Health Nursing, 21(10), 857-858. https://doi.org/10.1111/jpm.12183

DeHue, F., Bolman, C., \& Völlink, T. (2008). Cyberbullying: Youngsters' experiences and parental perception.

CyberPsychology \& Behavior, 11(2), 217-223. https://doi.org/10.1089/cpb.2007.0008

Dupper, D. R. (2013). School Bullying. New perspectives on a growing problem. Oxford University Press.

Dutton, D. G., \& Karakanta, C. (2013). Depression as a risk marker for aggression: A critical review. Aggression and Violent Behavior, 18(2), 310-319. https://doi.org/10.1016/j.avb.2012.12.002

Espelage, D. L., \& Holt, M. K. (2013). Suicidal ideation and school bullying experiences after controlling for depression and delinquency. Journal of Adolescent Health, 53(Suppl. 1), S27-S31. https://doi.org/10.1016/j.jadohealth.2012.09.017

Fahy, A. E., Stansfeld, S. A., Smuk, M., Smith, N. R., Cummins, S., \& Clark, C. (2016). Longitudinal associations between cyberbullying involvement and adolescent mental health. Journal of Adolescent Health, 59(5), 502-509.

https://doi.org/10.1016/j.jadohealth.2016.06.006

Hawker, D. S., \& Boulton, M. J. (2000). Twenty years' research on peer victimization and psychosocial maladjustment: A meta-analytic review of cross-sectional studies. Journal of Child Psychology and Psychiatry, 41(4), 441-455.

https://doi.org/10.1111/1469-7610.00629

Hinduja, S., \& Patchin, J. W. (2010). Bullying, cyberbullying, and suicide. Archives of Suicide Research, 14(3), $206-221$. https://doi.org/10.1080/13811118.2010.494133

Hinduja, S., \& Patchin, J. (2015). Bullying beyond the schoolyard: Preventing and responding to cyberbullying (2nd ed.). Corwin Press.

Kofoed, J., \& Staksrud, E. (2019). 'We always torment different people, so by definition, we are no bullies': The problem of definitions in cyberbullying research. New Media \& Society, 21(4), 1006-1020.

https://doi.org/10.1177/1461444818810026

Kokkinos, C. M., Antoniadou, N., \& Markos, A. (2014). Cyber-bullying: An investigation of the psychological profile of university student participants. Journal of Applied Developmental Psychology, 35(3), 204-214.

https://doi.org/10.1016/j.appdev.2014.04.001

Kowalski, R. M., \& Limber, S. P. (2013). Psychological, physical, and academic correlates of cyberbullying and traditional bullying. Journal of Adolescent Health, 53(Suppl. 1), S13-S20. https://doi.org/10.1016/j.jadohealth.2012.09.018 
Lien, L., \& Welander-Vatn, A. (2013). Factors associated with the persistence of bullying victimization from 10th grade to 13th grade: A longitudinal study. Clinical Practice and Epidemiology in Mental Health, 9, 243-250.

https://doi.org/10.2174/1745017901309010243

Livingstone, S., Haddon, L., Görzig, A., \& Ólafsson, K. (2011). Risks and safety on the Internet: The perspective of European children: Full findings and policy implications from the EU Kids Online survey of 9-16 year olds and their parents in 25 countries. EU Kids Online. http://eprints.Ise.ac.uk/33731/

Modecki, K. L., Barber, B. L., \& Vernon, L. (2013). Mapping developmental precursors of cyber-aggression: Trajectories of risk predict perpetration and victimization. Journal of Youth and Adolescence, 42(5), 651-661.

https://doi.org/10.1007/s10964-012-9887-z

Monks, C. P., Mahdavi, J., \& Rix, K. (2016). The emergence of cyberbullying in childhood: Parent and teacher perspectives. Psicología Educativa, 22(1), 39-48. https://doi.org/10.1016/j.pse.2016.02.002

Mossige, S., \& Stefansen, K. (2016). Vold og overgrep mot barn og unge: Omfang og utviklingstrekk 2007-2015 [Violence and abuse towards children: Time trends 2007-2015] (NOVA report 5/16). Nova. http://www.hioa.no/Om-

OsloMet/Senter-for-velferds-og-arbeidslivsforskning/NOVA/Publikasjonar/Rapporter/2016/Vold-og-overgrep-motbarn-og-unge

Nansel, T. R., Craig, W., Overpeck, M. D., Saluja, G., \& Ruan, W. J. (2004). Cross-national consistency in the relationship between bullying behaviors and psychosocial adjustment. Archives of Pediatrics \& Adolescent Medicine, 158(8), 730736. https://doi.org/10.1001/archpedi.158.8.730

Naruskov, K., Luik, P., Nocentini, A., \& Menesini E. (2012). Estonian students' perception and definition of cyberbullying. Trames, 16(4), 323-343. https://doi.org/10.3176/tr.2012.4.02

Nixon, C. L. (2014). Current perspectives: The impact of cyberbullying on adolescent health. Adolescent Health, Medicine and Therapeutics, 5, 143-158. https://doi.org/10.2147/AHMT.S36456

Olweus, D. (1994). Bullying at school: Long-term outcomes for the victims and an effective school-based intervention program. In L. R. Huesmann (Ed.), Aggressive behavior: Current perspectives (pp. 97-130). Springer.

https://doi.org/10.1007/978-1-4757-9116-7_5

Olweus, D. (2012). Cyberbullying: An overrated phenomenon? European Journal of Developmental Psychology, 9(5), 520-538. https://doi.org/10.1080/17405629.2012.682358

Patchin, J. W., \& Hinduja, S. (2006). Bullies move beyond the schoolyard a preliminary look at cyberbullying. Youth Violence and Juvenile Justice, 4(2), 148-169. https://doi.org/10.1177/1541204006286288

Paul, S., Smith, P.K., \& Blumberg, H. H. (2012). Revisiting cyberbullying in schools using the quality circle approach. School Psychology International, 33(5), 492-504. https://doi.org/10.1177/0143034312445243

Pelfrey, W. V. Jr., \& Weber, N. L. (2013). Keyboard gangsters: Analysis of incidence and correlates of cyberbullying in a large urban student population. Deviant Behavior, 34(1), 68-84. https://doi.org/10.1080/01639625.2012.707541

Plutchik, R. (1995). Outward and inward directed aggressiveness: The interaction between violence and suicidaliy. Pharmacopsychiatry, 28(Suppl. 2), 47-57. https://doi.org/10.1055/s-2007-979620

Rice, E., Petering, R., Rhoades, H., Winetrobe, H., Goldbach, J., Plant, A., Montoya, J., \& Kordic, T. (2015). Cyberbullying perpetration and victimization among middle-school students. American Journal of Public Health, 105(3), 66-72. https://doi.org/10.2105/AJPH.2014.302393

Sandanger, I., Moum, T., Ingebrigtsen, G., Dalgard, O. S., Sørensen, T., \& Bruusgaard, D. (1998). Concordance between symptom screening and diagnostic procedure: The Hopkins Symptom Checklist-25 and the Composite International 
Diagnostic Interview I. Social Psychiatry and Psychiatric Epidemiology, 33(7), 345-354.

https://doi.org/10.1007/s001270050064

Schneider, B., Lukaschek, K., Baumert, J., Meisinger, C., Erazo, N., \& Ladwig, K.-H. (2014). Living alone, obesity, and smoking increase risk for suicide independently of depressive mood findings from the population-based MONICA/KORA Augsburg cohort study. Journal of Affective Disorders, 152-154, 416-421.

https://doi.org/10.1016/j.jad.2013.10.007

Schneider, S. K., O'donnell, L., Stueve, A., \& Coulter, R. W. S. (2012). Cyberbullying, school bullying, and psychological distress: A regional census of high school students. American Journal of Public Health, 102(1), 171-177.

https://doi.org/10.2105/AJPH.2011.300308

Selkie, E. M., Kota, R., Chan, Y.-F., \& Moreno, M. (2015). Cyberbullying, depression, and problem alcohol use in female college students: A multisite study. Cyberpsychology, Behavior, and Social Networking, 18(2), 79-86.

https://doi.org/10.1089/cyber.2014.0371

Shapka, J. D., \& Maghsoudi, R. (2017). Examining the validity and reliability of the cyber-aggression and cybervictimization scale. Computers in Human Behavior, 69, 10-17. https://doi.org/10.1016/j.chb.2016.12.015

Slonje, R., Smith, P. K., \& Frisén, A. (2013). The nature of cyberbullying, and strategies for prevention. Computers in Human Behavior 29(1), 26-32. https://doi.org/10.1016/j.chb.2012.05.024

Smith, P. K., Mahdavi, J., Carvalho, M., Fisher, S., Russell, S., \& Tippett, N. (2008). Cyberbullying: Its nature and impact in secondary school pupils. Journal of Child Psychology and Psychiatry, 49(4), 376-385. https://doi.org/10.1111/j.14697610.2007.01846.x

Smith, P. K., \& Slonje, R. (2010). Cyberbullying: The nature and extent of a new kind of bullying, in and out of school. In S. R. Jimerson, S. M. Swearer, \& D. L. Espelage (Eds.), Handbook of bullying in schools: An international perspective (pp. 249-262). Routledge/Taylor \& Francis Group.

Sontag, L. M., Clemans, K. H., Graber, J. A., \& Lyndon, S. T. (2011). Traditional and cyber aggressors and victims: A comparison of psychosocial characteristics. Journal of Youth and Adolescence, 40(4), 392-404.

https://doi.org/10.1007/s10964-010-9575-9

Sourander, A., Brunstein Klomek, A., Ikonen, M., Lindroos, J., Luntamo, T., Koskelainen, M., Ristkari, T., \& Helenius, H. (2010). Psychosocial risk factors associated with cyberbullying among adolescents: A population-based study. Archives of General Psychiatry, 67(7), 720-728. https://doi.org/10.1001/archgenpsychiatry.2010.79

Statistics Norway. (2016). Norsk mediebarometer [Norweigan media barometer]. https://www.ssb.no/kultur-ogfritid/artikler-og-publikasjoner/_attachment/303444?_ts=15c1173e920

Stein, J. A., Dukes, R. L., \& Warren, J. I. (2007). Adolescent male bullies, victims, and bully-victims: A comparison of psychosocial and behavioral characteristics. Journal of Pediatric Psychology, 32(3), 273-282.

https://doi.org/10.1093/jpepsy/js1023

Sticca, F., Ruggieri, S., Alsaker, F., \& Perren, S. (2013). Longitudinal risk factors for cyberbullying in adolescence. Journal of Community \& Applied Social Psychology, 23(1), 52-67. https://doi.org/10.1002/casp.2136

Tabachnick, B. G., Fidell, L. S., \& Osterlind, S. J. (2001). Using multivariate statistics. Allyn and Bacon.

Tokunaga, R. S. (2010). Following you home from school: A critical review and synthesis of research on cyberbullying victimization. Computers in Human Behavior, 26(3), 277-287. https://doi.org/10.1016/j.chb.2009.11.014

Tural Hesapcioglu, S., \& Ercan, F. (2017). Traditional and cyberbullying co-occurrence and its relationship to psychiatric symptoms. Pediatrics International, 59(1), 16-22. https://doi.org/10.1111/ped.13067 
van Geel, M., Vedder, P., \& Tanilon, J. (2014). Relationship between peer victimization, cyberbullying, and suicide in children and adolescents: A meta-analysis. JAMA Pediatrics, 168(5), 435-442.

https://doi.org/10.1001/jamapediatrics.2013.4143

Wade, A., \& Beran, T. (2011). Cyberbullying: The new era of bullying. Canadian Journal of School Psychology, 26(1), 4461. https://doi.org/10.1177/0829573510396318

Wang, J., lannotti, R. J., \& Luk, J. W. (2012). Patterns of adolescent bullying behaviors: Physical, verbal, exclusion, rumor, and cyber. Journal of School Psychology, 50(4), 521-534. https://doi.org/10.1016/j.jsp.2012.03.004

Wang, J., lannotti, R. J., \& Nansel, T. R. (2009). School bullying among adolescents in the United States: Physical, verbal, relational, and cyber. Journal of Adolescent Health, 45(4), 368-375. https://doi.org/10.1016/j.jadohealth.2009.03.021

Wendelborg, C. (2012). Mobbing, diskriminering og uro i klasserommet. Analyse av Elevundersøkelsen 2012 [Bullying, discrimination and unrest in the classroom. Analysis of the Pupil Survey 2012]. NTNU. https://www.udir.no/tall-ogforskning/finn-forskning/rapporter/Elevundersokelsen-2012---analyse-av-mobbing-uro-og-diskriminering/

Wright, V. H., Burnham, J. J., Inman, C. T., \& Ogorchock, H. N. (2014). Cyberbullying: Using virtual scenarios to educate and raise awareness. Journal of Computing in Teacher Education, 26(1), 35-42.

https://doi.org/10.1080/10402454.2009.10784629

Yao, M. Z., \& Flanagin, A. J. (2006). A self-awareness approach to computer-mediated communication. Computers in Human Behavior, 22(3), 518-544. https://doi.org/10.1016/j.chb.2004.10.008

Ybarra, M. L., \& Mitchell, K. J. (2004). Online aggressors/targets, aggressors, and targets: A comparison of associated youth characteristics. Journal of Child Psychology and Psychiatry,45(7), 1308-1316. https://doi.org/10.1111/j.14697610.2004.00328.x 


\section{Correspondence to:}

Sara Skilbred-Fjeld

University of Oslo, Department of Psychology

Forskningsveien 3A

Oslo 0373

Norway

Email: sara_fjeld(at)hotmail.com

Editorial record: First submission received on March 3, 2018. Revisions received on March 20, 2019, November 6, 2019 and January 30, 2020. Accepted for publication on January 30, 2020.

Editor in charge: Lenka Dedkova

\section{About Authors}

Sara Skilbred-Fjeld has a master's degree in psychology from the University of Oslo. Her master thesis was about psychological characteristics of adolescents involved in cyberbullying. Skilbred-Fjeld has worked as a research assistant at the Department of Media and Communication, where she was involved in a research project about European children's online opportunities, risks and safety (EU Kids Online). She has also been involved in The Norwegian Social Research Institute's research project about domestic violence. Currently, she is writing a non-fictional book about how increased stress levels in the population can be understood in the context of labor pressure related to the idea of unlimited economic growth.

Dr. Silje Endresen Reme works as a professor of health psychology at University of Oslo, and as a clinical psychologist at the Department of Pain Management and Research at Oslo University Hospital. She has worked as a senior researcher at Uni Research Health, where she co-headed the research group Stress, Health and Rehabilitation. Dr. Reme has longstanding interests in the field of work and health, disability, and rehabilitation. Her research focuses on chronic pain conditions and mental health problems in working life, with a particular focus on risk disability factors and interventions to improve outcomes.

Svein Mossige is a professor in clinical child psychology, Department of Psychology, University of Oslo. His research fields include violence and sexual abuse in families, self-harm and resilience, and pediatric psychology. 